\title{
Unravelling the social network of COVID-19 in India from 30 January to 6 April 2020
}

\author{
Sarita $\mathrm{Azad}^{1 *}$ Sushma Devi ${ }^{2}$ \\ ${ }^{1}$ School of Basic Sciences, Indian Institute of Technology Mandi, 175075, India. \\ ${ }^{2}$ School of Basic Sciences, Indian Institute of Technology Mandi, 175075, India.
}

*corresponding author sarita@iitmandi.ac.in

\begin{abstract}
Social network analysis is an essential means to uncover and examine infectious contact relations between individuals. This paper aims to investigate the spread of coronavirus disease (COVID-19) from international to the national level and find a few super spreaders which played a central role in the transmission of disease in India. Our network metrics calculated from 30 January to 6 April 2020 revealed that the maximum numbers of connections were established from Dubai (degree-144) and UK (degree-64). These two countries played a crucial role in diffusing the disease in Indian states. The eigenvector centrality of Dubai is found to be the highest, and this marked it the most influential node. However, based on the modularity class, we found that the different clusters were formed across Indian states which demonstrated the forming of a multi-layered social network structure.

A significant increase in the confirmed cases was reported during the first lockdown 1.0 (22 March 2020) primarily attributed to a gathering in Delhi Religious Conference (DRC) known as Tabliqui Jamaat. As of 6 April 2020, the overall structure of the network has encompassed local transmission, and it was significantly seen in the states like Gujarat, Rajasthan, and Karnataka. An important conclusion drawn from the presented social network reveals that the COVID-19 spread till 6 April was mainly due to the local transmission across Indian states. The timely quarantine of infected cases in DRC has not led it to spread at the level of community transmission.
\end{abstract}




\section{Keywords: COVID-19; India; Indian states; International travels; Local transmission; Community transmission; Delhi religious conference.}

\section{Introduction}

In December 2019, China reported several cases of unusual pneumonia in Wuhan province to the World Health Organization (WHO) country office ${ }^{1}$. In the following weeks, the virus spread in China and then across the borders and reached all over the world. The outbreak was declared a Public Health Emergency of International Concern on 30 January 2020. On 11 February 2020, WHO announced a name for the new coronavirus disease: COVID-19².

In India, the first case was reported on 30 January 2020 from Wuhan, China. In the absence of any cure, this disease could have been fatal for a vast country like India, affecting the 1.3 billion population. However, the infection rate of COVID-19 in India was reported to be 1.7 , which is remarkably lower than the other affected countries ${ }^{3}$. This slow spread could be mainly due to timely country lockdown 1.0 which was commenced on 24 March 2020 for 21 days $^{4}$. To control this pandemic Indian government enacted a range of social distancing strategies, such as city-wide lockdown, screening measures at train stations and airports, and isolation of suspected cases ${ }^{5}$. Furthermore, widespread vaccination for tuberculosis or resistance to malaria has helped India remain immune to the pandemic to some extent. Perhaps, due to these reasons, the rate of infection in India was slow ${ }^{6}$. As of 10 April, India's five worst-hit states were Maharashtra, Delhi, Tamil Nadu, Rajasthan and Telangana and these were declared as hotspots in terms of the total number of COVID-19 infections ${ }^{7}$.

In the initial phase, the transmission of COVID-19 was mainly due to international travels. A large number of Indians and foreigners travelled from countries like UK, UAE, Italy, Wuhan, Dubai, USA, Saudi Arabia, Iran, Philippines, Thailand, and Indonesia to Indian states. Transmission of disease which spreads through contact among the people can increase the risk of an outbreak. But to understand how these diseases spread among the people remains a challenge. The explosion of devastating infections, such as SARS (2003), Ebola (2014-2015), and Zika (2015-2016), have shown that the dynamics behind the spread of disease is more complex and limit our ability to predict and control epidemics. Therefore, contact patterns can be used to analyze the dynamics of the disease. A network can be inferred through statistical metrics like degree, modularity, centrality, etc., these are the essential factors which quantify a network ${ }^{8-9}$. Social networks generally represent the 
connections in the form of a graph where individuals are nodes and lines connecting them are edges. Edges represent the strength of interaction and can either be undirected or bidirectional. In summary, social-network analysis (SNA) ${ }^{10-16}$ provides methods to measure the social interactions in a population, which in turn can quantify the social structure of an occurrence. Measures of centrality (degree, strength, eigenvector centrality, and closeness) are typically the most directly relevant metrics to disease research because they measure vital aspects of an individual's connectivity or importance to overall social structure. Most real networks typically find parts in which the nodes are more highly connected than to the rest of the network. The sets of such nodes are usually called clusters, communities, cohesive groups, or modules. The community detection problem (CDP) is defined as the division of a graph into clusters or groups of nodes where each one includes a robust internal cohesion (i.e. densities of edges within a group), and a week external cohesion (i.e. outside the group). Some well-known methods are documented in the literature that allows constructing such communities in the form of clusters known as modularity ${ }^{17-20}$. In the present work, the network has been created on Gephi software (version 0.9.2) which makes use of the Louvain method for community detection ${ }^{21}$.

The main objective of this paper is to provide social network behind the spread of COVID-19 in India; it will demonstrate the situation from the beginning and how it outbreaks the balloon in Indian states through cluster formation. The presented work will be an essential contribution as fewer studies are available on the COVID-19 transmission network as a whole.

\section{Results and discussion}

Fig. 1 depicts a social network formed of contacts from 10 countries (these contacts may be Indians or foreigners) and 24 Indian states which mainly took part in the initial transmission of disease through international travelling. A real network typically comprises of nodes (units); in our case, countries are the primary nodes and represent a one-directional flow of information to Indian states. Fig.1 also shows small nodes in which patient numbers are marked, whereas each edge represents the travelling detail of the infected patient from any one of the countries to Indian states.

In Figure 2, the number of international travels to the Indian states are listed. It is found that the highest numbers of international contacts were established in Kerala from different countries. For example, people travelled from Dubai to Kerala were 90, from UAE to Kerala were 24, etc. State-wise data is provided in Figure 2. 


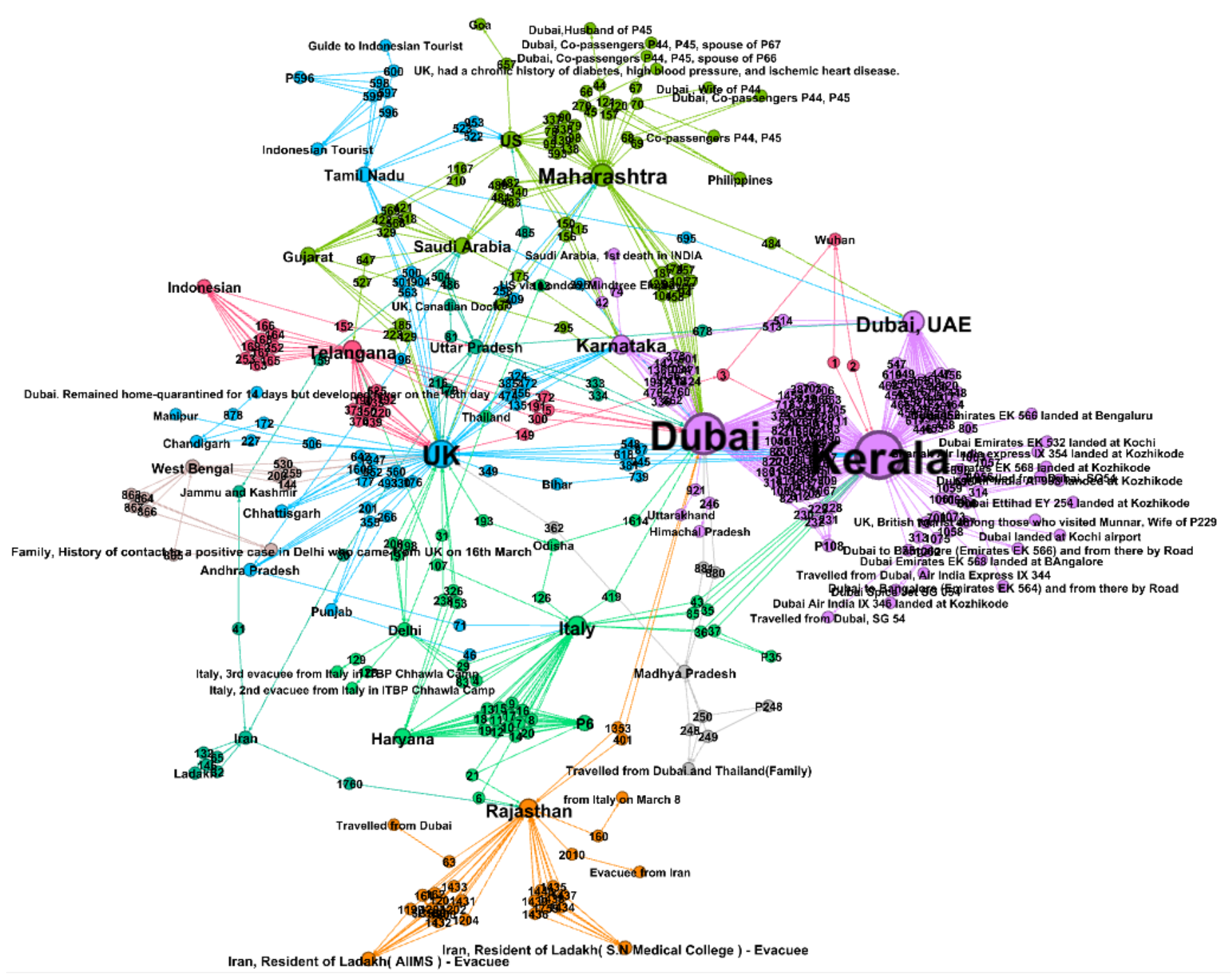

Figure 1: Network showing the International flow of people to the Indian states in the initial phase of COVID19 spread. Nodes size is proportional to the number of connections. A zoom at higher resolution reveals that it is made of several clusters.

It is evident from the figure that the maximum number of people have travelled from Dubai and UK to Indian states. For example, from UK people have gone to 18 different states, whereas from Dubai, it is 15 states. Further, Table 1 summarises the metrics which quantity the connections in Figure 1. It is seen that degree of Dubai and UK is 144 and 69, respectively, which shows the highest links established in various states from these two countries. Also, Table 1 shows that Dubai and UK have the highest closeness centrality (i.e. closeness to all other nodes) which means these two countries were the main point of diffusion as these two are connected with the maximum number of nodes. Further, it is seen from Table 1 that the UK has a high modularity class (i.e. the number of clusters) then Dubai, which means that the people who have travelled from the UK formed a large number of 
groups across Indian states. Therefore, we can conclude from Table 1 (also seen in Figure 1) that travellers from the UK have played the central role in transmitting the disease in India, where Dubai has highest eigenvector centrality which means it was the most influential node.

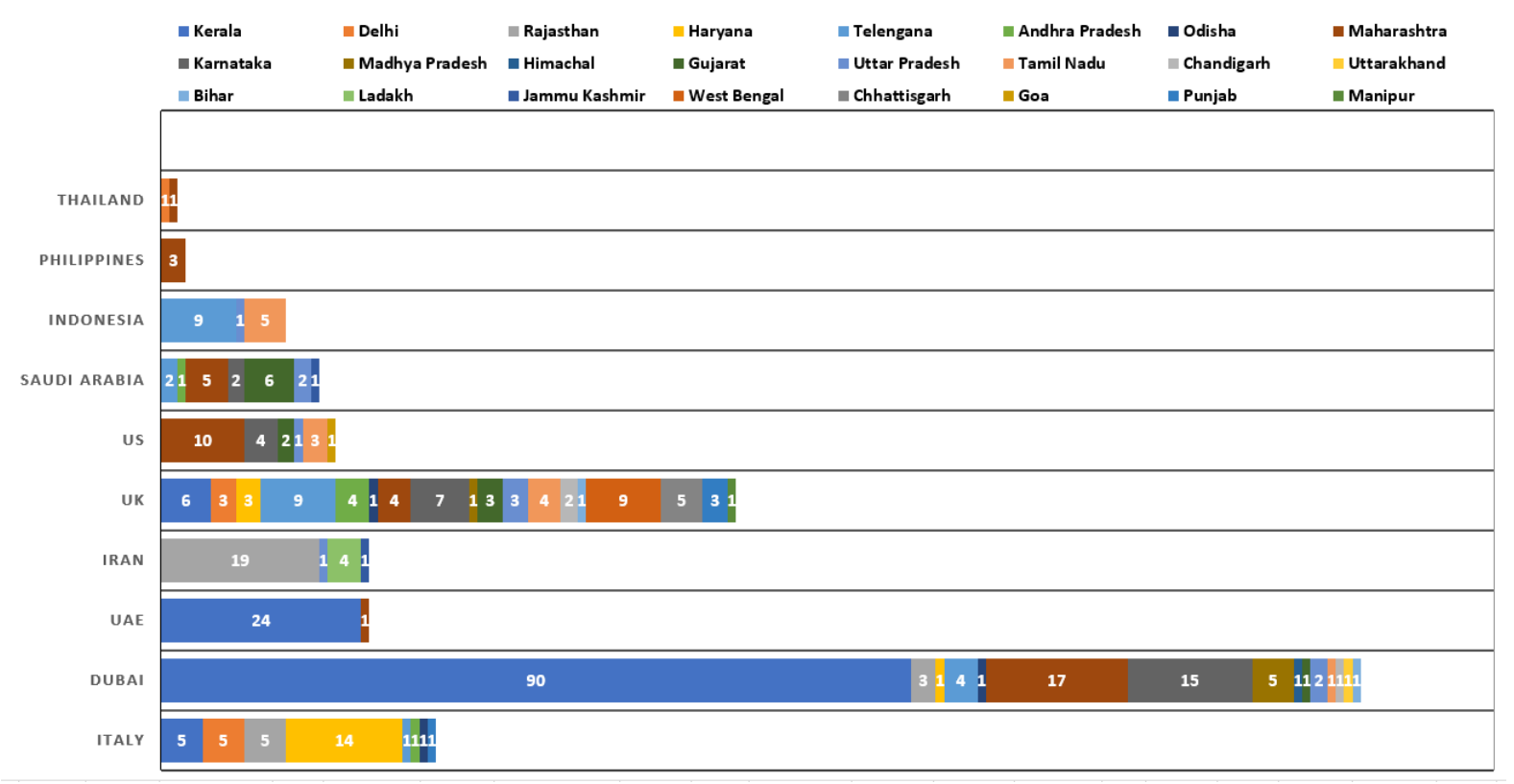

Figure 2: Number of infected people travelled from different countries to various Indian states.

Figure 3 shows a social network which is mainly constituted to demonstrate the local transmission and interstate spread of COVID-19. A religious conference organized in Delhi's Nizamuddin area, also known as Delhi Religious Conference (DRC), started from 13 March 2020 had become a significant force in the spread of COVID-19 in India. For this event, over 3400 people had gathered at Nizamuddin Markaz as a part of the religious gathering and around 1300 were sent back to their respective states during the lockdown period. Table 2 summarise the metrics which quantity the connections in Figure 3. It is seen from the table that a maximum number of infected cases (degree-385) had been traced in Tamil Nadu, Delhi (degree-301), followed by Andhra Pradesh (degree-138), Assam (degree-24), and Uttar Pradesh (11) from DRC. However, it is interesting to note that although the degree of connections is very high in these states due to DRC, they have formed very less number of clusters outside their community. For example, modularity class of Andhra Pradesh is one, Delhi two and Tamil Nadu three, and so on, which shows that the transmission due to DRC remained confined to few states. 


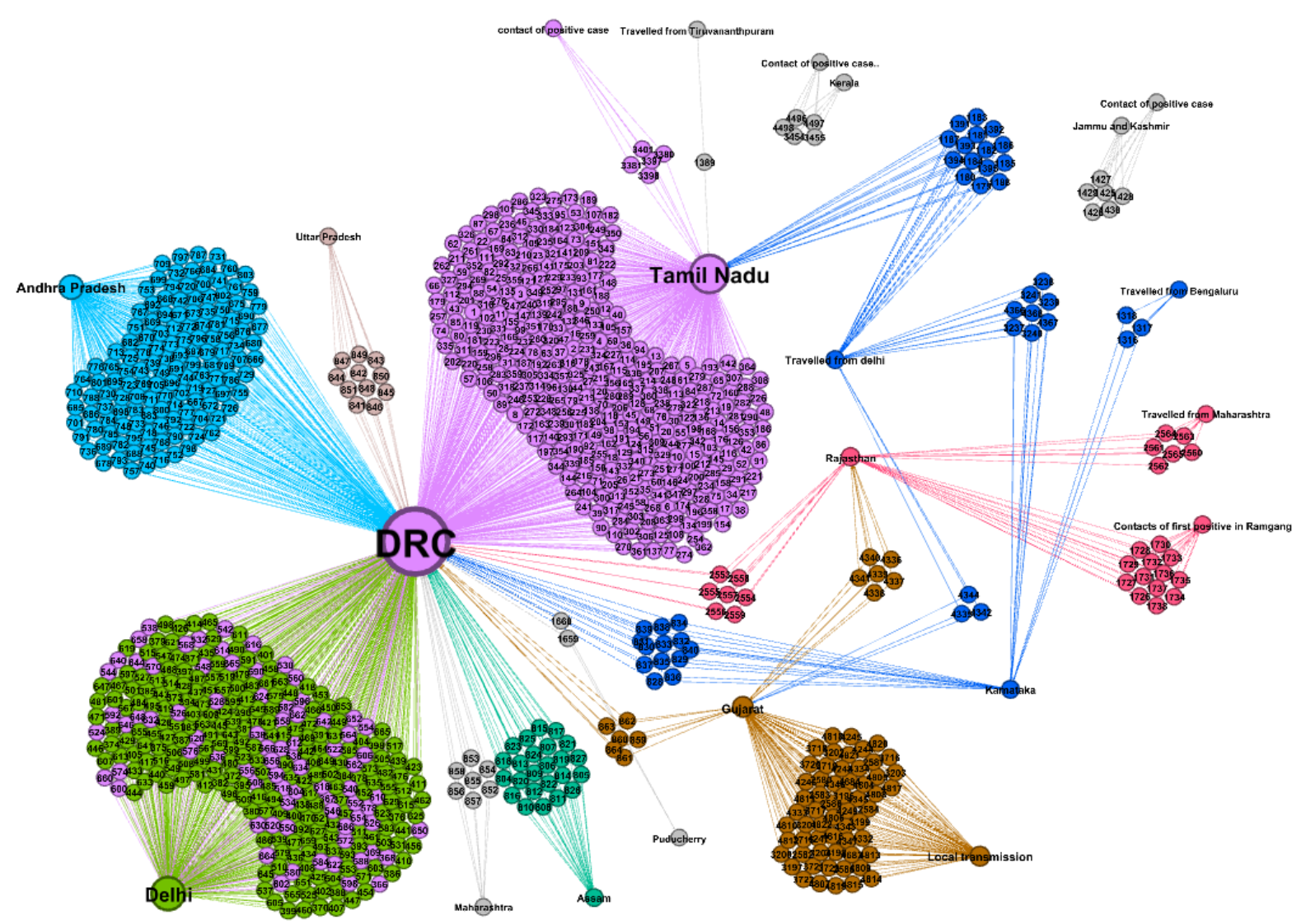

Figure 3: A contact network including the Delhi Religious Conference (DRC) social interactions.

Further, it is observed from the Table 2 that although other states have less number of degrees (e.g. Gujarat, degree-74; Rajasthan, degree-32) they have formed a large number of clusters (Gujarat 7; Rajasthan 12). From the data, contacts of first positive cases have been located mainly in states like Kerala, Jammu, and Rajasthan. These connections are shown in Figure 3. Further, to understand the local and inter-state transmission, we have magnified a part of Figure 3 in Figure 4. It shows high local transmission in Gujarat, Rajasthan and Maharashtra which is due to the formation of a large number of clusters, although the number of connections from DRC is low. Similarly, Figure 4 shows that the modularity class of Karnataka is 8 , and it has formed clusters across different states demonstrating a multilayered social network structure. 


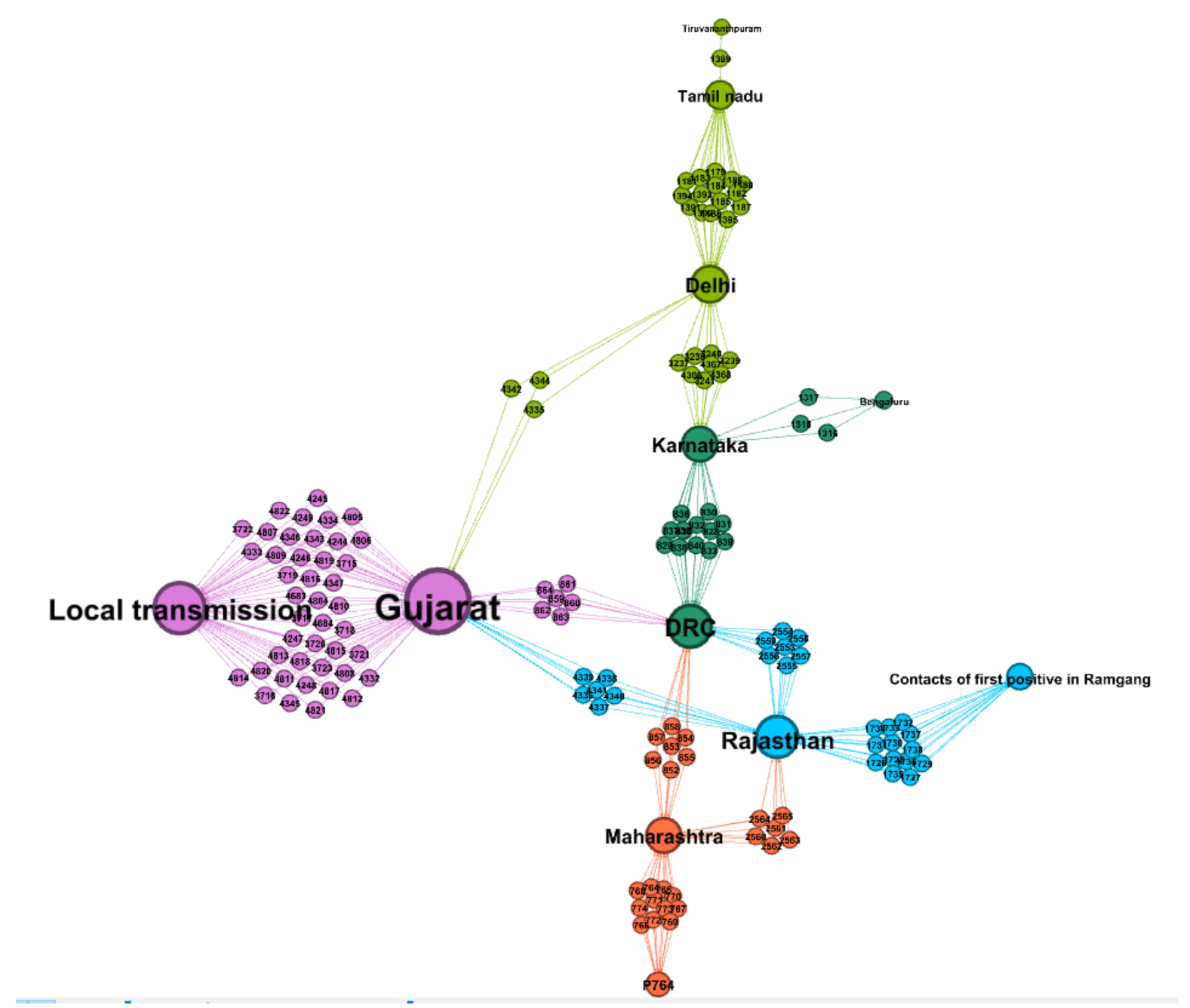

Figure 4: A network of local transmission.

To summarise, four distinct stages of COVID-19 have been identified so far ${ }^{22}$. The stage- 1 is when a disease is imported from affected countries without any local origin, and it has not spread locally. Stage-2 is the phase of local transmission, which includes people who have travel history to other already affected countries. Stage- 3 is the phase of community transmission where the source of an infected individual can not be traced and isolated. Once the population enters into Stage-3, the individuals contract the infections randomly, and it becomes difficult to track the disease.

Hence, we have concluded that the transmission of COVID-19 in India remained at the local level (Stage-2) as of 6 April 2020. Besides the burst of an outbreak due to DRC, it didn't develop into community transmission (Stage-3) because of the timely quarantine of infected cases in Delhi. 


\section{Conclusions:}

The network analysis of social contacts reveals that in the initial phase of transmission, large numbers of regional connections were established mainly from countries like Dubai and UK. From the statistical metric, it is found that Dubai had a degree of 144, and its eigenvector centrality was highest. However, an interesting observation is that the modularity class (number of clusters) formed from the UK is seven. Therefore, we can conclude that the UK has played a central role in transmitting the disease in India, where Dubai has the highest eigenvector centrality, which means it was the most influential node. Further, we found that modularity class from the states like Tamil Nadu, Delhi, Andhra Pradesh who have attended the DRC is very low. Hence, it is likely that their role in the spread of the disease outside their community was less. On the other hand, it was found that Gujarat, Rajasthan, and Maharashtra played a significant role in the local transmission, whereas Karnataka in the inter-state transfer.

The conclusion stands as COVID-19 spread in India was mainly through local transmission until lockdown 1.0, and has not gone up to the level of community transmission ${ }^{23}$.

\section{Data availability:}

Data utilized in the present study is obtained from https://www.covid19india.org, which includes the patient number, the state they belong to, their travelling history and source. In this study, we have included total 1386 cases of infections, out of which 373 are international and 1013 are national contacts. The data is considered from 30 January to 6 April 2020 and the network has been created on Gephi software (version 0.9.2).

\section{References}

[1] Chan, JF-W et al. A familial cluster of pneumonia associated with 118 the 2019 novel coronavirus indicating person-to-person transmission: a study of a 119 family cluster. Lancet. January (2020). doi:10.1016/S0140-6736(20)30154-9

[2] World Health Organization. Novel Coronavirus-China Disease Outbreak News. Available online: https://www.who.int/csr/don/12-january-2020-novel-coronavirus-china/en/ [3] Ying Liu, Albert A Gayle, Annelies Wilder-Smith, Joacim Rocklöv, The reproductive number of COVID-19 is higher compared to SARS coronavirus, Journal of Travel Medicine, 27(2) (2020), taaa021, https://doi.org/10.1093/jtm/taaa021 
[4] India coronavirus: Modi announces 21-day nationwide lockdown, limiting movement of 1.4bn people, The Independent, 24 March 2020.

[5] https://www.indiatoday.in/india/story/5-states-worst-hit-by-coronavirus-in-india-a-quicklook-at-the-numbers-1665388-2020-04-10?ref=taboola

[6] https://qz.com/india/1839018/why-does-india-have-so-few-coronavirus-covid-19-casesand-deaths/

[7] https://www.ndtv.com/india-news/indias-coronavirus-lockdown-clear-roads-clean-air$\underline{80 s-t v-2209373}$

[8] Bell, D. C., Atkinson, J. S. \& Carlson, J. W. Centrality measures for disease transmission networks. Soc. Netw. 21, 1-21 (1999).

[9] Newman, M. E. J. Networks: An Introduction (Oxford University Press, 2016).

[10] Matthew, J. Silk et al. McDonald, Using Social Network Measures in Wildlife Disease Ecology, Epidemiology, and Management, BioScience, 67(3), 245-257 (2017) https://doi.org/10.1093/biosci/biw175

[11] Palla, G., Derényi, I., Farkas, I. et al. Uncovering the overlapping community structure of complex networks in nature and society. Nature 435, 814-818 (2005). https://doi.org/10.1038/nature03607

[12] Bansal, S., Read, J., Pourbohloul, B. \& Meyers, L. A. The dynamic nature of contact networks in infectious disease epidemiology. J. Biol. Dynam. 4, 478-489 (2010).

[13] Watts, D. J. \& Strogatz, S. H. Collective dynamics of small-world networks. Nature 393, 440-442 (1998).

[14] Vicsek, T. The bigger picture. Nature 418, 131 (2002)

[15] Girvan, M. \& Newman, M. E. J. Community structure in social and biological networks. Proc. Natl.Acad. Sci. USA 99, 7821-7826 (2002).

[16] Yang, C.H., Jung, H. Topological dynamics of the 2015 South Korea MERS-CoV spread-on-contact networks. Sci Rep 10, 4327 (2020). https://doi.org/10.1038/s41598-02061133-9

[17] Newman, M. E. J. Modularity and community structure in networks. Proc. Natl Acad. Sci. USA 103(23), 8577-8582 (2006).

[18] Fortunato, S. Community detection in graphs. Phys. Rep. 486, 75-174 (2010)

Handcock, M. S., Raftery, A. E. \& Tantrum, J. M. Model-based clustering for social networks. J. Roy. Stat. Soc. A 170, 301-322 (2007)

[19] Kashtan, N. et al. Extinctions in heterogeneous environments and the evolution of modularity. Evolution 63, 1964-1975 (2009) 
[20] Expert, P., Evans, T. S., Blondel, V. D. \& Lambiotte, R. Uncovering space independent communities in spatial networks. Proc. Natl Acad. Sci. USA 108, 7663-7668 (2011)

[21]Blondel,V. D., Guillaume, J.L, Lambiotte, R., Lefebvre, E. Fast unfolding of communities in large networks. Journal of Statistical Mechanics: Theory and Experiment

10

P10008 (2008)

doi: $10.1088 / 1742-5468 / 2008 / 10 / \mathrm{P} 10008$.

[22] https://www.netmeds.com/health-library/post/covid-19-the-4-stages-of-disease$\underline{\text { transmission-explained }}$

[23] https://www.hindustantimes.com/india-news/covid-19-in-local-transmission-notcommunity-transmission-says-govt/story-cgXXr5GZWRPdLsedPIihAM.html

Table 1: A summary of network metrics obtained from Figure 1.

\begin{tabular}{|l|c|c|c|c|c|}
\hline $\begin{array}{l}\text { S. } \\
\text { no }\end{array}$ & Country & Degree & $\begin{array}{c}\text { Closeness } \\
\text { centrality }\end{array}$ & $\begin{array}{c}\text { Modularity } \\
\text { class }\end{array}$ & $\begin{array}{c}\text { Eigenvector } \\
\text { centrality }\end{array}$ \\
\hline 1 & Dubai & 144 & 0.3424 & 2 & 0.8146 \\
\hline 2 & UK & 69 & 0.3156 & 7 & 0.4397 \\
\hline 3 & Italy & 32 & 0.2439 & 1 & 0.2018 \\
\hline 4 & UAE & 39 & 0.2532 & 2 & 0.2811 \\
\hline 5 & USA & 20 & 0.2008 & 9 & 0.1441 \\
\hline 6 & Saudi Arabia & 19 & 0.2126 & 9 & 0.1297 \\
\hline 7 & Indonesia & 15 & 0.1873 & 8 & 0.0720 \\
\hline 8 & Iran & 25 & 0.1907 & 5 & 0.0504 \\
\hline 9 & Wuhan & 3 & 0.2162 & 8 & 0.0267 \\
\hline 10 & Philippines & 3 & 0.1784 & 9 & 0.0216 \\
\hline 11 & Thailand & 2 & 0.1854 & 1 & 0.0144 \\
\hline
\end{tabular}


Table 2: A summary of network metrics obtained from Figure 2.

\begin{tabular}{|c|l|c|c|c|c|}
\hline S. No. & \multicolumn{1}{|c|}{$\begin{array}{c}\text { State's DRC } \\
\text { connection }\end{array}$} & Degree & $\begin{array}{c}\text { Modularity } \\
\text { Class }\end{array}$ & $\begin{array}{c}\text { Closeness } \\
\text { Centrality }\end{array}$ & $\begin{array}{c}\text { Eigenvector } \\
\text { Centrality }\end{array}$ \\
\hline 1 & Tamil Nadu & 385 & 3 & 0.412 & 0.441 \\
\hline 2 & Delhi & 301 & 2 & 0.374 & 0.344 \\
\hline 3 & Andhra Pradesh & 138 & 1 & 0.334 & 0.158 \\
\hline 4 & Assam & 24 & 4 & 0.310 & 0.027 \\
\hline 5 & Uttar Pradesh & 11 & 5 & 0.308 & 0.012 \\
\hline 6 & $\begin{array}{l}\text { Maharashtra } \\
\text { (Local transmission) }\end{array}$ & 13 & 6 & 0.307 & 0.008 \\
\hline 7 & $\begin{array}{l}\text { Gujarat } \\
\text { (Local transmission) }\end{array}$ & 74 & 7 & 0.346 & 0.084 \\
\hline 8 & $\begin{array}{l}\text { Rajasthan } \\
\text { (Local transmission) }\end{array}$ & 32 & 12 & 0.331 & 0.036 \\
\hline 9 & $\begin{array}{l}\text { Karnataka } \\
\text { (Inter-state } \\
\text { transmission) }\end{array}$ & 24 & 8 & 0.317 & 0.027 \\
\hline
\end{tabular}

